\title{
“A SPOONFUL OF SUGAR” - TRANS-ALVEOLAR NUTRITION
}

\author{
J.R. Hewson and A.J.C. Holland
}

THE LUNG HAS been shown to utilize a number of exogenous substrates, including dextrose, ${ }^{1}$ through the pulmonary vascular tree, and it has likewise been demonstrated that surfactant production and alveolar membrane activity depend a great deal on substrate metabolism. ${ }^{2,3,4}$

The question arises as to whether the lungs are capable of utilizing substrate such as dextrose presented from the airway rather than the vascular route. If such were indeed the case, then bronchial substrate administration could conceivably support alveolar cell metabolism and surfactant production during low flow states such as shock, thereby preventing development of progressive pulmonary failure which accounts for one-third of deaths seen in severely injured patients. ${ }^{5}$

It was decided to examine the effects of intra-luminal 5 per cent dextrose and insulin solution on the cellular metabolism of the isolated non-perfused, non-ventilated rabbit lung. The solutions chosen for purpose of comparison were normal saline, which is not a substrate source; a 5 per cent 3-O-methyl glucose solution with insulin; and, finally, a 5 per cent dextrose and insulin solution. 3-O-methyl glucose has been shown to be transported in the same manner as dextrose, but is not metabolized; ${ }^{6}$ insulin was added both to the 3-O-methyl glucose solution and to the dextrose solution for it has recently been reported that addition of insulin as well as dextrose to the perfusate appears to be beneficial in maintaining integrity at the biochemical and functional level of isolated normothermic lung perfused with blood. ${ }^{7}$

\section{Materials AND Methods}

Adult albino rabbits weighing between two and three kilograms were used as the experimental animal. They were sacrificed by the rapid injection of $750 \mathrm{mgm}$ of pentobarbitone into a marginal ear vein. The lungs were immediately excised and isolated, and each main stem bronchus was cannulated with a short length of epidural catheter which was firmly tied in place. While the first lung was being cannulated the second was placed in ice-cold saline. The time taken between injection of pentobarbitone and complete isolation and cannulation of both lungs varied between five and eight minutes.

Three groups of four rabbits each were used initially and each animal acted as its own control. In the first group of rabbits $10.0 \mathrm{ml}$ of normal saline was instilled through the epidural catheters into the bronchial tree of each isolated lung. This was a volume large enough to produce substantial lung distension. Then one lung from each animal was placed in ice-cold saline, while the second was incubated

From the Department of Anaesthesia, Montreal General Hospital, and McGill University, Montreal, P.Q. 
for 30 minutes at a temperature of between $32^{\circ} \mathrm{C}$ and $34^{\circ} \mathrm{C}$ in a fully humidified room-air atmosphere. At the end of this period of time the second lung also was put into ice-cold saline. As rapidly as possible thereafter a tissue sample from each lung was homogenized and analyzed for lactic acid in the manner described by McArdle et al. ${ }^{8}$ and for adenosine triphosphate (A.T.P.) according to the method described by Forte et al. ${ }^{9}$

The second group differed in that the solution employed was 5 per cent 3-Omethyl glucose $9.8 \mathrm{ml}$ together with $0.2 \mathrm{ml}$ of normal saline containing a total of 0.2 unit of soluble insulin, in each lung. Otherwise, however, incubation times and A.T.P. and lactate assays were exactly the same.

For the third group, the solution employed was 5 per cent dextrose $(9.8 \mathrm{ml})$ with $0.2 \mathrm{ml}$ of normal saline and insulin solution as in group 2. Both lungs were treated as before and the same estimations were done.

After these initial groups of measurements had been performed, the lungs of a fourth group of four rabbits were prepared in the same way, and a direct comparison was made between 5 per cent dextrose and 5 per cent 3-O-methyl glucose. One lung of each animal was filled with $9.8 \mathrm{ml}$ of 5 per cent glucose together with $0.2 \mathrm{ml}$ of insulin solution, while the other was filled with $9.8 \mathrm{ml}$ of 5 per cent 3-Omethyl glucose and $0.2 \mathrm{ml}$ of the insulin solution. Each was then incubated and, at the end of 30 minutes, lactate and A.T.P. determinations were made.

To act as a final control and as a verification of methodology, a fifth and final group of four rabbits was sacrificed in the same way as the preceding groups. In this series, however, lung biopsies were taken immediately upon thoracotomy, and A.T.P. and lactate levels were measured. This was done to obtain some base-line levels, as nowhere in the literature is there mention of normal A.T.P. and lactate values for lung tissue in the non-manipulated lung.

\section{RESULTS}

\section{A.T.P. Maintenance}

Examination of Table I shows that in all rabbits, no matter what solution was administered intraluminally into the lungs, there was a statistically significant fall in A.T.P. levels after incubation for 30 minutes ( $p<0.01 ; p<0.02 ; p<0.05)$.

The maintenance of tissue A.T.P. was least in the normal saline group ( 38.2 per cent of control values), intermediate in the 3-O-methyl glucose/insulin group ( 48.8 per cent) and greatest in the dextrose/insulin group ( 62.3 per cent). The average A.T.P. percentage maintained in each group differed significantly from those of the other two groups (normal saline to OMG/insulin, normal saline to dextrose/insulin, and OMG/insulin to dextrose/insulin, had $\mathrm{p}$ values of $<0.05$, 0.01 , and 0.01 respectively).

Of probably even greater significance, however, were the results presented in Table II. Here glucose/insulin and 3-O-methyl glucose/insulin solutions were compared in the same animal after 30 minutes of incubation. The results demonstrate A.T.P. levels which, with glucose/insulin, are 156.8 per cent of those obtained with 3-O-methyl glucose/insulin $(p<0.05)$ thus verifying the A.T.P. sparing of glucose/insulin previously demonstrated in Table $\mathrm{I}$. 
HEWSON \& HOLLAND: TRANS-ALVEOLAR NUTRITION

TABLE I

Pulmonary Levels of A.T.P. (IN micromoles/Gm tissue) Before AND AFTER 30 MinUtes ANaEROBIC INCUBATION WiTH InTRALUMinal SOLution

\begin{tabular}{lcccc}
\hline Group & Animal & Control & $30 \mathrm{~min}$ & $\frac{30 \mathrm{~min}}{\text { Control }} \times 100 \%$ \\
\hline Normal Saline & 1 & 0.690 & 0.000 & $0.0 \%$ \\
& 2 & 1.000 & 0.530 & $53.0 \%$ \\
& 3 & 1.570 & 0.920 & $58.6 \%$ \\
& 4 & 0.730 & 0.300 & $41.1 \%$ \\
& Mean & 0.998 & 0.438 & $38.2 \% \mathrm{p}<0.01$ \\
O.M.G. (9.8 ml) & 1 & 0.690 & 0.380 & $55.1 \%$ \\
and Insulin & 2 & 0.750 & 0.240 & $32.0 \%$ \\
$(0.2$ units in & 3 & 1.400 & 0.770 & $55.0 \%$ \\
0.2 ml saline $)$ & 4 & 0.490 & 0.260 & $53.1 \%$ \\
& Mean & 0.833 & 0.413 & $48.8 \% \mathrm{p}<0.02$ \\
D.W (9.8 ml) & 1 & 2.210 & 1.350 & $61.1 \%$ \\
and Insulin & 2 & 1.120 & 0.550 & $49.1 \%$ \\
(0.2 units in & 3 & 1.070 & 0.550 & $51.4 \%$ \\
0.2 ml saline) & 4 & 1.130 & 1.000 & $88.5 \%$ \\
& Mean & 1.383 & 0.863 & $62.3 \% \mathrm{p}<0.05$ \\
\hline
\end{tabular}

TABLE II

Pulmonary Levels of A.T.P. (IN Micromoles/GM tissue) Following 30 Minutes anaerobic Incubation with Intraluminal Solution

\begin{tabular}{cccc}
\hline & \multicolumn{2}{c}{ Intraluminal solution } & \\
\cline { 2 - 3 } Animal & $\begin{array}{c}\text { O.M.G. and } \\
\text { insulin }\end{array}$ & $\begin{array}{c}\text { Glucose and } \\
\text { insulin }\end{array}$ & $\begin{array}{c}\text { Glucose and insulin } \\
\text { O.M.G. and insulin }\end{array} \times 100 \%$ \\
\hline 1 & 0.280 & 0.450 & $161 \%$ \\
2 & 0.300 & 0.420 & $140 \%$ \\
3 & 0.340 & 0.570 & $168 \%$ \\
4 & 0.584 & 0.920 & $158 \%$ \\
Mean & 0.376 & 0.590 & $157 \%(\mathrm{p}<0.05)$ \\
\hline
\end{tabular}

\section{Lactate Production}

Lactate levels before and after 30 minutes incubation with each of the three solutions are shown in Table III. In the lungs incubated with bronchial normal saline, lactate levels rose to 261.3 per cent of control values $(p<0.01)$. The 3-Omethyl glucose/insulin solution had no significant changes in lung lactate levels with incubation ( 96.2 per cent, non-significant). The lungs incubated with bronchial glucose/insulin had lactate levels 222.6 per cent of control values $(p<0.10)$. Comparing these three groups with each other, the increase with the normal saline group differed significantly from the $O M G /$ insulin group $(p<0.02)$, and the increase with the dextrose/insulin was just outside significant levels $(p<0.10)$ relative to the $\mathrm{OMG} /$ insulin group.

Table IV gives the lactate values in the fourth group of animals, comparing incubation with dextrose/insulin and 3-O-methyl glucose/insulin in the same animal. Lactate levels in the dextrose/insulin lungs were 180.0 per cent of those in the 3-O-methyl glucose/insulin lungs $(\mathrm{p}<0.20)$. 
TABLE III

Pulmonary Lactate Levels (In mg/Gm tissue) Before and After 30 Minutes ANAEROBIC INCUBation WITH INTRALUMINAL SOLUTION

\begin{tabular}{lcccc}
\hline \hline Group & Animal & Control & $30 \mathrm{~min}$ & $\frac{30 \mathrm{~min}}{\text { Control }} \times 100 \%$ \\
\hline Normal Saline & 1 & 0.294 & 0.517 & $\mathbf{1 7 5 . 9 \%}$ \\
& 2 & 0.167 & 0.640 & $383.2 \%$ \\
& 3 & 0.341 & 0.766 & $224.6 \%$ \\
& 4 & 0.247 & 0.646 & $261.5 \%$ \\
& Mean & 0.262 & 0.642 & $261.3 \% \mathrm{p}<0.01$ \\
O.M.G (9.8 ml) & 1 & 0.505 & 0.435 & $86.1 \%$ \\
and Insulin & 2 & 0.543 & 0.247 & $45.5 \%$ \\
(0.2 units in & 3 & 0.557 & 0.799 & $143.4 \%$ \\
0.2 ml saline) & 4 & 0.143 & 0.157 & $109.8 \%$ \\
& Mean & 0.439 & 0.410 & $96.2 \%$ Non-significant \\
D5/W (9.8 ml) & 1 & 0.449 & 0.438 & $97.6 \%$ \\
and Insulin & 2 & 0.191 & 0.647 & $338.7 \%$ \\
(0.2 units in & 3 & 0.487 & 0.679 & $139.4 \%$ \\
0.2 ml saline) & 4 & 0.240 & 0.755 & $314.6 \%$ \\
& Mean & 0.342 & 0.630 & $222.6 \%$ p < 0.10 \\
\hline
\end{tabular}

TABLE IV

Pulmonary Lactate Levels (in mg/Gm tissue) Following 30 Minutes of ANaERohic InCUbation With Intraluminal SOlution

\begin{tabular}{cccc}
\hline \hline & \multicolumn{2}{c}{ Intraluminal Solution } & \\
\cline { 2 - 3 } Animal & $\begin{array}{c}\text { O.M.G. and } \\
\text { insulin }\end{array}$ & $\begin{array}{c}\text { Glucose and } \\
\text { insulin }\end{array}$ & $\begin{array}{c}\text { Glucose and insulin } \\
\text { O.M.G. and insulin }\end{array} \times 100 \%$ \\
\hline 1 & 0.206 & 0.431 & $209 \%$ \\
2 & 0.167 & 0.485 & $290 \%$ \\
3 & 0.576 & 0.506 & $88 \%$ \\
4 & 0.524 & 0.698 & $133 \%$ \\
Mean & 0.368 & 0.530 & $180 \%(\mathrm{p}<0.20)$ \\
\hline
\end{tabular}

\section{Correlation Between A.T.P. and Lactate Levels}

In the eight lungs incubated with dextrose/insulin and the eight incubated with 3-O-methyl glucose, there was significant correlation between A.T.P. levels and lactate levels $(r=0.689$, S.E. $=0.258$ ), as shown in Figure 1. There was no signifcant correlation if the lungs incubated with normal saline were included $(r=0.417$, S.E. $=0.229$ ). There was likewise no correlation between A.T.P. and lactate levels in the control groups taken collectively $(r=0.441$, S.E. $=0.301)$.

\section{Controls}

Table $\mathrm{V}$ indicates the pulmonary tissue A.T.P. and lactate values obtained in four rabbits with no experimental manipulation. The low values of the standard deviations for the A.T.P. values and the lactate levels attest to the reliability of the laboratory methodology used in making these determinations in the animals in experimental groups I to IV. 


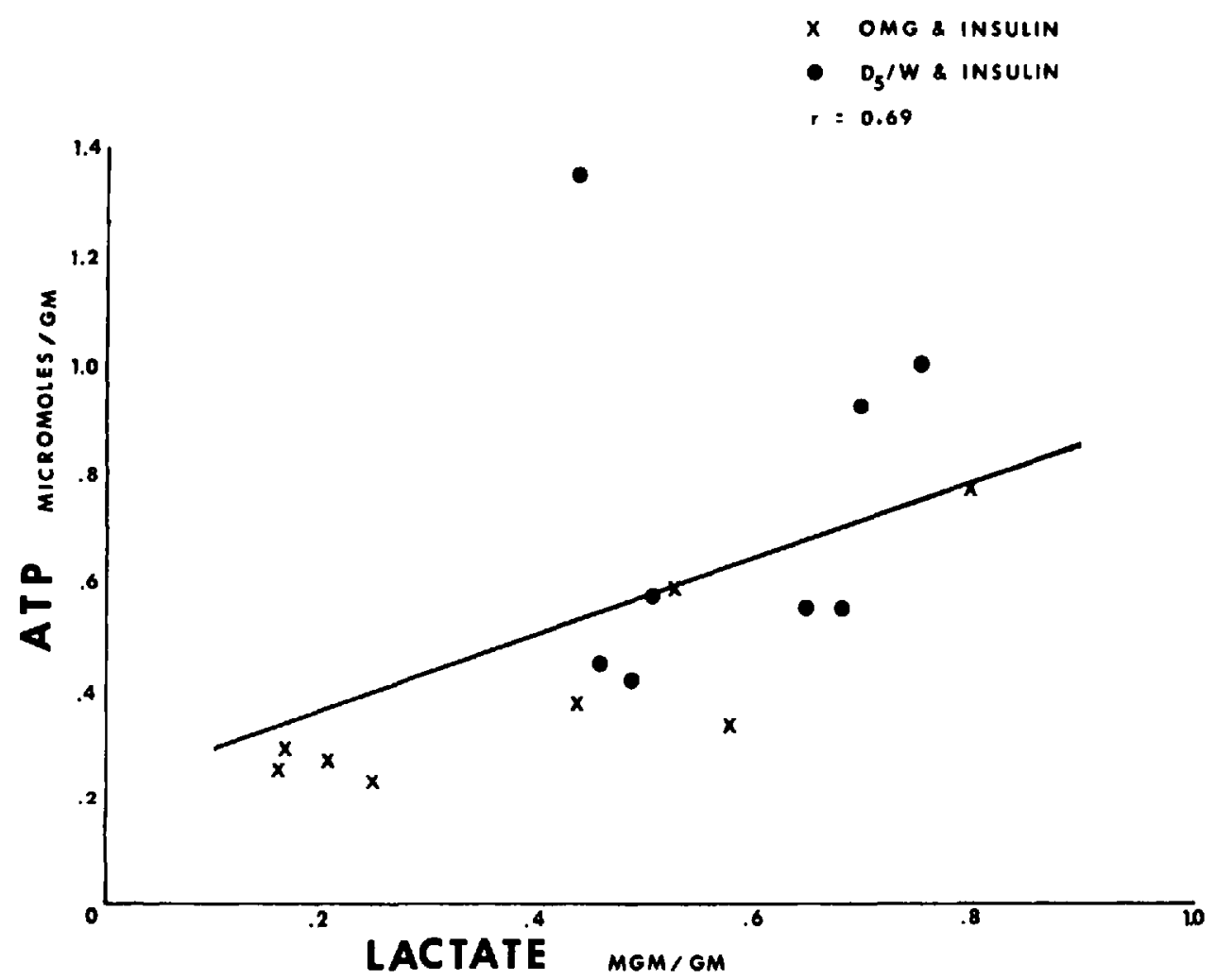

Ficure 1. Correlation between A.T.P. and Lactate levels.

TABLE V

Pulmonary Levels of A.T.P. and Laćtate Without Intraluminal INFUSION OF FLUID

\begin{tabular}{ccc}
\hline & A.T.P. (micromoles/gram \\
of tissue) & $\begin{array}{c}\text { Lactate (milligrams/gram } \\
\text { of tissue) }\end{array}$ \\
\hline 1 & 0.980 & 0.470 \\
2 & 1.190 & 0.400 \\
3 & 0.880 & 0.409 \\
4 & 0.940 & 0.313 \\
Mean \pm S.D. & $0.998 \pm 0.135$ & $0.398 \pm 0.065$ \\
\hline
\end{tabular}

\section{Discussion}

It has been proposed by many that depletion of tissue energy stores is the primary mechanism underlying the ultimate collapse and death of animals and man in various forms of shock. ${ }^{10-12}$ One often finds, in association with shock and/or trauma, progressive pulmonary insufficiency characterized by interstitial and alveolar oedema, with hyaline and fibrinous deposits, and histological alterations of the alveolar lining cells. ${ }^{13}$ Depletion of surfactant in the pulmonary insufficiency. syndrome is thought to be due to inadequate perfusion and oxygenation of the alveolar lining cells. ${ }^{14}$ 
It is clearly established that the lung is a metabolically active organ.,15,16 Surfactant production and structural integrity have been shown to be intimately related to subtrate metabolism. ${ }^{2-4}$ Addition of dextrose and insulin to the perfusate has been found beneficial in maintaining the integrity of the isolated normothermic blood perfused canine lung. ${ }^{7}$ The canine lung has been found capable of utilizing carbohydrate almost exclusively for its energy requirements. ${ }^{15}$

The intestine, kidney and lung each possesses epithelially lined lumina and each seems to be particularly prone to damage in conditions of shock or poor perfusion. It has been amply demonstrated by McArdle et al. ${ }^{8}$ that the canine intestine can be significantly protected by the presence of intraluminal glucose during shock. The intestine, unlike the lung, is specifically designed to absorb nutrients from its lumen. The lung is obviously highly efficient at absorbing and transporting gases, such as oxygen and carbon dioxide, and vapours, such as halothane and methoxyflurane, and has likewise long been known to be capable of absorbing aerosols of compounds such as isoproterenol which affect the activity of its bronchiolar musculature. There appears to be no information, however, as to the ability of the lung to absorb from the airway substances which could be utilized locally by the alveolar cells to maintain their own metabolism. If the lung does indeed possess the ability to absorb and to utilize effectively energy substrate presented through the airway and support alveolar cell metabolism and surfactant production, this could constitute a significant advance in the management of pulmonary insufficiency associated with the "shock lung" syndrome.

It was therefore decided to investigate the ability of the lung to utilize glucose and insulin presented through the bronchus. The experimental model used in the present paper was deliberately uncomplicated in its design in order to obtain resolution of this question. The results appear to demonstrate metabolic support of the isolated rabbit lung by bronchial and intra-alveolar glucose and insulin under anaerobic conditions, as indicated by maintenance of A.T.P. levels.

Consideration of the lactate-A.T.P. correlation is of some interest. Because of the anaerobic nature of the experimental model, it is not surprising that there is significant correlation between these two substances following the anaerobic incubation with the 3-O-methyl glucose/insulin and dextrose/insulin solutions.

One must conclude that some substrate is stored in the lung even after incubation with saline. However, the lack of A.T.P.-lactate correlation in the normal saline group cannot be easily explained at present. There may be increased use of A.T.P. to maintain a normal intracellular sodium concentration in the face of intra-luminal (extra-cellular) saline. Also, the low levels of lactate in the O.M.G./insulin group may be due to increased utilization of alternative pathways of glucose catabolism secondary to the addition of insulin. An example of this is the phosphogluconate oxidative pathway, ${ }^{17}$ and such pathways may be important in fatty acid synthesis and carbohydrate metabolism in the presence of insulin. If these suppositions were indeed true, then A.T.P. would correlate with lactate levels and would be relatively higher in the insulin-containing groups than in the normal saline group which did not contain insulin. If glucose was added to insulin, then one could expect to see increased lactate levels with correlating increases in A.T.P. This is indeed what has been seen in our experiments. 
Whatever the explanation, it appears from these experimental data that the lung is capable of utilizing glucose and insulin from its airway luminal surface under anaerobic conditions and to maintain A.T.P. levels. This suggests that intraluminal (alveolar) substrate will maintain alveolar cell activity.

Further experiments are required to validate more completely the authors' hypothesis that alveolar glucose can be used as a means of providing lung nutrition. For instance, it may be said that the metabolic role of A.T.P. has been over-simplified, and indeed it is true that A.T.P. levels do only tell a small part of the story of lung function. It is also impossible to tell what the effect of pentobarbitone is on alveolar cell metabolism, although by using pentobarbitone in all the rabbits, both control and experimental, this unknown effect can probably be ignored for the purpose of this study. These points notwithstanding, this study has shown that simple bronchial instillation of glucose solution into the isolated, non-perfused lung seems to have a significant effect as far as the maintenance of A.T.P. levels of pulmonary tissue is concerned.

A logical extension of this would be to instill glucose solution as an aerosol into the alveoli in order to maintain alveolar cell activity, as it is already established that 90 per cent of an aerosol composed of submicronic particles reaches the level of the alveoli. ${ }^{18}$ It is not beyond the bounds of possibility that adequate ventilation combined with submicronic aerosol energy substrate, such as glucose (perhaps combined with insulin), might be of benefit in the prophylaxis and therapy of pulmonary insufficiency secondary to such conditions as sepsis, pulmonary trauma, aspiration, head injury and fat embolization, in which progressive pulmonary failure may be a troublesome and often fatal complication. ${ }^{19}$

Studies, at present in progress, will attempt to test the feasibility of instilling submicronic particles of substrate into the lungs in order to maintain alveolar cell viability, and will suggest whether such procedures will ever have clinical application.

\section{SUMMARY}

In this initial study, it has been postulated that even the simple bronchial administration of isotonic glucose and insulin can maintain alveolar cell metabolism as measured by A.T.P. activity; further studies, using aerosolized glucose solutions, will test the validity of the hypothesis that alveolar metabolism can be maintained by the administration of substrate in aerosolized form by the alveolar route and will determine whether this form of substrate administration has clinical potential.

\section{RÉSUMÉ}

Une première étude permet de penser que la simple administration endobronchique de glucose isotonique et d'Insuline peut maintenir le métabolisme cellulaire alvéolaire, tel que démontré par la mesure de lactivité A.T.P. Poursuivant ces travaux avec des solutions de glucose en aérosols, nous chercherons à vérifier l'hypothèse que le métabolisme cellulaire peut ètre maintenu de cette manière et explorerons le potentiel clinique d'une telle approche. 


\section{ACKNOWLEDGMENTS}

The authors would like to acknowledge the help and advice they received from the Department of Experimental Surgery, Montreal General Hospital, in particular Dr. A.H. McArdle and Heidi and Vreni Siegrist. This project was supported in part by a grant from the Women's Auxiliary, Montreal General Hospital, to whom thanks are also due.

\section{REFERENCES}

1. Rhoades, R.A. Net uptake of glucose, glycerol and fatty acids by the isolated perfused rat lung. Am. J. Physiol. 226: 144-149 (1974).

2. KENNEDY, E.P. The metabolism and function of complex lipids. Harvey Lectures ser. 57 : 143-171 (1961-62).

3. Klaus, M., Reiss, O.K., Tooley, W.H., Piel, C., \& Clements, J.A. Alveolar epithelial cell mitochondria as a source of surface-active lining material. Science 137: 750-751 (1962).

4. Thomas, T. Jr. \& Rhoades, R.A. Incorporation of palmitate-1-14C into lung tissue lecithin and alveolar lecithin. Am. J. Physiol. 219: 1535-1538 (1970).

5. Moore, F.D., Lyons, J.H., Puerce, E.C., Morgan, A.P., Drinker, P.A., MacArthur, J.P., \& Dammin, G.J. Post-traumatic pulmonary insufficiency. W.B. Saunders Co. (1969).

6. Csaky, T.Z. \& WILSON, J.E. The fate of $3-\mathrm{O}-{ }^{14} \mathrm{CH}_{3}$-glucose in the rat. Biochim. Biophys. Acta 22: 185-186 (1956).

7. Modry, D.L., Jirsch, D.W., BoehMe, G., Fisk, R.L., \& Couves, C.M. Perfusion of the isolated lung: The role of glucose and insulin in the perfusate. Can. J. Surg. (in press).

8. McArdie, A.H., Chiv, C.J., \& Gurd, F.N. Intraluminal glucose: substrate for ischemic intestine. Arch Surg. 105: 441-445 (1972).

9. Forte, J.J., Adams, P.H., \& Davies, R.E. Acid secretion and phosphate metabolism in bullfrog gastric mucosa. Biochim. Biophys. Acta 104: 28-38 (1965).

10. Crowell, J.W., Jones, C.E., \& SMith, E.E. Effect of allopurinol on haemorrhagic shock. Am. J. Physiol, 216: 744-748 (1969).

11. Loiselle, J.M. \& Denstedt, O.F. Biochemical changes during acute physiological failure in the rat II. The behaviour of adenine and pyridine nucleotides of the liver during shock. Can. J. Biochem. 42: 21-34 (1964).

12. McShaw, W.H., Potter, V.R., Goldman, A., Shipley, E.G., \& Meyer, R.K. Biological energy transformations during shock as shown by blood chemistry. Am. J. Physiol. 145: 93-106 (1945).

13. Dowd, J. \& Jenkins, L.C. The lung in shock: a review. Canad. Anaesth. Soc. J. 19: 309-318 (1972).

14. Henry, J.W., McArdele, A.H., Scott, H.J., \& Gurd, F.N. A study of the acute and chronic respiratory pathophysiology of haemorrhagic shock. J. Thor. and Cardiovasc. Surg. 54: 666-678 (1967)

15. Weber, K.C. \& Visscher, M.B. Metabolism of the isolated canine lung. Am. J. Physiol. 217: 1044-1052 (1969).

16. Rubenstein, A.H., Zwi, S., \& Millen, K. Insulin and the lung. Diabetologia 4: 236-238 (1968).

17. White, A., Handeer, P., Smirk, E.L., \& Stetten DeWrtr JR. Carbohydrate metabolism: The phosphogluconate oxidative pathway. Principles of biochemistry (2nd ed.). New York. McGraw-Hill, pp. 411-413 (1959).

18. Deutrebande, L. Deposition of air-borne particles, Microaerosols p. 78, New York, (Academic Press) ( 1962 ).

19. Horovitz, J.H., Carrico, C.J., \& Shires, T. Pulmonaty responses to major injury. Arch. Surg. 108: 349-355 (1974). 